\title{
Pengaruh Variabel Pemahaman K3 dan Kepatuhan K3 terhadap target Zero Accident
}

\author{
Nureni Kenpurwastuti ${ }^{1, *}$, Dayal Gustopo Setiadjit ${ }^{2}$, Prima Vitasari ${ }^{3}$ \\ ${ }^{1}$ Pengawas Ketenagakerjaan Dinas Tenaga Kerja dan Transmigrasi Provinsi Jawa Timur \\ ${ }^{2,3}$ Program Studi Teknik Industri S-2, Pascasarjana, Institut Teknologi Nasional (ITN) Malang \\ *E-mail: erastiwahono@gmail.com
}

\begin{abstract}
Abstrak
PT. Malidas Sterilindo di Kabupaten Sidoarjo telah beberapa kali berhasil mendapatkan penghargaan zero accident (kecelakaan nilhil) dari Pemerintah Republik Indonesia sejak tahun 2011 hingga tahun 2019. Perusahaan ini menerapkan Sistem Manajemen Keselamatan dan Kesehatan Kerja (SMK3) untuk mempertahankan zero accident. Dalam pelaksanaannya masih terdapat beberapa unsafe condition, unsafe action, nearmiss, dan accident yang dapat menyebabkan gagalnya zero accident yang diprogramkan perusahaan. Penelitian ini menganalisis pengaruh antara pemahaman K3 dan kepatuhan pada K3 terhadap zero accident. Dilakukan survey terhadap 100 responden dengan menyebarkan kuesioner yang berisi 30 pertanyaan.Teknik analisis data adalah dengan uji korelasi dan regresi linier berganda. Hasil penelitian menunjukkan bahwa zero accident dipengaruhi secara positif signifikan oleh variabel pemahaman K3 dan variabel kepatuhan pada k3 dengan kontribusi sebesar 34,9\%. Pemahaman K3 (X1) berpengaruh positif terhadap Kepatuhan pada K3 (X2) dengan koefisien regresi sebesar 64,1\%. Pemahaman $\mathrm{K} 3\left(\mathrm{X}_{1}\right)$ berpengaruh positif terhadap Zero accident $(\mathrm{Y})$ dengan koefisien regresi sebesar $57,6 \%$. Kepatuhan pada $\mathrm{K} 3\left(\mathrm{X}_{2}\right)$ berpengaruh positif terhadap Zero accident $(\mathrm{Y})$ dengan koefisien regresi sebesar $50,3 \%$. Selanjutnya hasil dari penelitian ini digunakan untuk membuat usulan program dalam rangka mempertahankan kecelakaan nihil melalui konsep continuous improvement (perbaikan berkelanjutan) dengan menggunakan metode PDCA (Plan-Do-Check-Action).
\end{abstract}

Kata Kunci: Continuous Improvement,Keselamatan dan Kesehatan Kerja (K3), Sistem Manajemen K3 (SMK3), Zero Accident, PDCA

\section{Pendahuluan}

Terjadinya kecelakaan di tempat kerja sebagian besar disebabkan oleh faktor manusia dan sebagian kecil disebabkan oleh faktor teknis [1,2].Penerapan SMK3 diperlukan untuk menjamin keselamatan dan kesehatan tenaga kerja maupun orang lain yang berada di tempat kerja, serta sumber produksi dan lingkungan kerja dalam keadaan aman [3,4]. Tujuan dari Sistem Manajemen K3 adalah merupakan suatu sistem keselamatan dan kesehatan kerja di tempat kerja yang melibatkan beberapa unsur, meliputi manajemen, tenaga kerja, kondisi, dan lingkungan kerja yang terintegrasi dalam upaya mencegah dan mengurangi kecelakaan dan penyakit akibat kerja serta terciptanya tempat kerja yang aman, efisien, dan produktif [5,6,7]. Sasaran dari penerapan program keselamatan dan kesehatan kerja adalah untuk meningkatkan kinerja dan produktifitas karyawan $[8,9,10,11]$.

Penelitian terdahulu dengan judul perencanaan kontrol kecelakaan kerja menuju zero accident pada industri pabrik gula NBH [12]. Tujuan penelitian adalah untuk mengetahui hasil model kontrol continuous improvement untuk mengurangi angka kecelakaan kerja pada stasiun kerja boiler di Pabrik Gula NBH. Hasil penelitian ini diperoleh model kontrol kecelakaan kerja menuju zero accident pada stasiun kerja boiler di Pabrik Gula NBH dengan metode perbaikan secara terus menerus (continuous improvement) dengan sistem PDCA (Plan-Do-Check-Action). Penanggulangan kecelakaan kerja memerlukan strategi agar tujuan kecelakaan nihil dapat tercapai [13]. Potensi-potensi bahaya dan risiko yang terdapat dalam pekerjaan harus diketahui sebelumnya untuk memberikan tindakan dalam mereduksi ataupun menghilangkan resiko pencegahan [14]. 
Tujuan penelitian di PT. Malidas Sterilindo Sidoarjo ini adalah untuk mengevaluasi pelaksanaan SMK3 dalam rangka mempertahankan zero accident. Dalam visi mempertahankan kecelakaan nihil maka komitmen, komunikasi, budaya keselamatan dan pembelajaran keselamatan merupakan hal yang sangat penting $[15,16]$. Standardisasi merupakan salah satu alat yang bisa digunakan dalam proses perbaikan berkelanjutan [17]. Pengetahuan, sikap, dan perilaku pekerja dapat mempengaruhi penerapan manajemen budaya keselamatan dan kesehatan kerja [18].Manfaat yang diharapkan dalam penelitian ini bagi perusahaan adalah agar dapat mencapai target untuk selalu mendapatkan penghargaan zero accident dengan mengimplementasikan rumusan strategi yang dibuat berdasarkan hasil penelitian.

\section{Metodologi Penelitian}

Pada penelitian ini dilakukan survey terhadap 100 responden dengan menyebarkan kuesioner yang berisi 30 pertanyaan.Teknik analisis data yang digunakan untuk mengolah data primer yang diperoleh dari pengumpulan data adalah Program SPSS (Statistical Product and Service Solution).Analisis yang digunakan dalam penelitian ini adalah analisis korelasi dan regresi berganda.

Beberapa hipotesis yang dianalisis dalam penelitian ini adalah sebagai berikut

- Hipotesis 1 yaitu $\mathrm{H}_{0}$ : Tidak terdapat pengaruh positif signifikan antara Pemahaman tentang K3 terhadap zero accident; $\mathrm{H}_{\mathrm{a}}$ : Terdapat pengaruh positif signifikan antara Pemahaman tentang K3 terhadap zero accident

- Hipotesis 2 yaitu $\mathrm{H}_{0}$ : Tidak terdapat pengaruh positif signifikan antara Kepatuhan pada $\mathrm{K} 3$ terhadap zero accident; $\mathrm{H}_{\mathrm{a}}$ : Terdapat pengaruh positif signifikan antara Kepatuhan pada $\mathrm{K} 3$ terhadap zero accident

- Hipotesis 3 yaitu $\mathrm{H}_{0}$ : Tidak terdapat pengaruh positif signifikan antara Pemahaman tentang K3 terhadap Kepatuhan pada K3; $\mathrm{H}_{\mathrm{a}}$ : Terdapat pengaruh positif signifikan antara Pemahaman tentang K3 terhadap Kepatuhan pada K3

- Hipotesis 4 yaitu $\mathrm{H}_{0}$ : Tidak terdapat pengaruh positif signifikan antara Pemahaman tentang $\mathrm{K} 3$ dan Kepatuhan pada $\mathrm{K} 3$ terhadap zero accident; $\mathrm{H}_{\mathrm{a}}$ : Terdapat pengaruh positif signifikan antara Pemahaman tentang K3 dan Kepatuhan pada K3 terhadap zero accident

\section{Hasil Penelitian}

Untuk mengetahui validitas dan reliabilitas dilakukan pengujian dengan hasil sebagai berikut :

1. Uji Validitas

Uji validitas yang digunakan dalam penelitian untuk menguji butir-butir pernyataan dengan menggunakan teknik analisis korelasi bivariate pearson. Persyaratan tingkat signifikan dengan dasar pengambilan keputusan adalah jika, nilai sig. dua sisi dibawah 0,05 maka data dapat dianggap valid. Adapun hasil pengujian validitas dijabarkan sebagai berikut:

Tabel 1. Uji Validitas

\begin{tabular}{|c|c|c|}
\hline Variabel & Nilai Sig. & Keterangan \\
\hline Pemahaman tentang K3 & 0,698 & Valid \\
\hline Kepatuhan pada K3 & 0,647 & Valid \\
\hline Zero accident & 0,596 & Valid \\
\hline
\end{tabular}

Sumber : Hasil Olah Data

Berdasarkan hasil Tabel uji validitas instrumen pada variabel Pemahaman tentang K3, variabel Kepatuhan pada $\mathrm{K} 3$ dan Zero accident diperoleh hasil bahwa nilai sig. pada masing-masing indikator dinyatakan valid dan dapat digunakan dalam penelitian.

2. Uji Reliabilitas

Untuk menguji reliabilitas dengan keputusan apabila koefisien cronbach alpha positif $\geq 0,6$ maka faktor tersebut dikatakan realibel. 
Tabel 2. Uji Reliabilitas

\begin{tabular}{|c|c|c|}
\hline Variabel & Nilai Alpha & Keterangan \\
\hline $\begin{array}{c}\text { Pemahaman tentang K3, } \\
\text { Kepatuhan pada K3, } \\
\text { Zero accident }\end{array}$ & 0,901 & Reliabel \\
\hline
\end{tabular}

Sumber : Hasil Olah Data

Berdasarkan hasil tabel uji reliabilitas instrumen pada variabel Pemahaman tentang K3, variabel Kepatuhan pada K3 dan Zero accident diperoleh hasil bahwa nilai pada masing-masing indikator dinyatakan reliabel dan dapat digunakan dalam penelitian.

\section{Uji Hipotesis Penelitian}

Uji hipotesis pada penelitian ini menggunakan uji korelasi dan regresi linier berganda. Uji korelasi dimaksud adalah untuk mengetahui besarnya hubungan pengaruh antara pemahaman tentang K3 terhadap zero accident, kepatuhan pada K3 terhadap zero accident, serta pemahaman tentang K3 terhadap kepatuhan pada K3. Uji regresi linier berganda dilakukan untuk Analisis ini digunakan untuk mengetahui pengaruh antara variabel pemahaman tentang K3 dan kepatuhan pada K3 terhadap zero accident. Berikut adalah hasiluji hipotesis yang diperoleh pada penelitian ini.

a. Uji korelasi antara pemahaman pada K3 terhadap zero accident

Pengujian Hipotesis I

$\mathrm{H}_{0}$ : Tidak terdapat pengaruh positif signifikan antara Pemahaman tentang K3 terhadap Zero accident

$\mathrm{H}_{\mathrm{a}}$ : Terdapat pengaruh positif signifikan antara Pemahaman tentang K3 terhadap Zero accident

Kriteria uji hipotesis adalah jika nilai signifikansi < 0,05 , maka $\mathrm{H}_{\mathrm{a}}$ diterima dan $\mathrm{H}_{0}$ ditolak; jika nilai signifikansi > 0,05, maka $\mathrm{H}_{\mathrm{a}}$ ditolak dan $\mathrm{H}_{0}$ diterima.

Tabel 3. Korelasi antara pemahaman tentang K3 terhadap zero accident

\begin{tabular}{|c|c|c|}
\hline & Pemahaman tentang K3 & Zero accident \\
\hline $\begin{array}{c}\text { Pemahaman Tentang K3 } \\
\text { Pearson corelation }\end{array}$ & 1 & .576 \\
Sig (2-tailed) & 100 &, 000 \\
N & & 100 \\
\hline Zero accident &, 576 & 1 \\
Pearson corelation &, 000 & 100 \\
Sig (2-tailed) & 100 & \\
N & & \\
\hline
\end{tabular}

Sumber : Hasil Olah Data

Berdasarkan tabel 3 diketahui nilai signifikansi sebesar $0,000<0,05$ sehingga $\mathrm{H}_{0}$ ditolak. Artinya "Terdapat pengaruh positif signifikan antara Pemahaman tentang K3 terhadap Zero accident". Koefisien pengaruh antara Pemahaman tentang K3 terhadap zero accident adalah sebesar $57,6 \%$. Pemahaman tentang K3 $\left(\mathrm{X}_{1}\right)$ berpengaruh positif terhadap Zero accident $(\mathrm{Y})$ dengan koefisien korelasi sebesar 0,576. Adanya hubungan positif ini berarti pemahaman tentang K3 memiliki hubungan yang searah. Nilai koefisien 0,576 dapat diartikan bahwa variabel Pemahaman tentang K3 mempunyai pengaruh sebesar 57,6\% terhadap variabel zero accident, artinya memiliki hubungan yang erat.

b. Uji korelasi antara kepatuhan pada K3 terhadap zero accident

Pengujian Hipotesis II

$\mathrm{H}_{0}$ : Tidak terdapat pengaruh positif signifikan antara Kepatuhan pada $\mathrm{K} 3$ terhadap Zero accident

$\mathrm{H}_{\mathrm{a}}$ : Terdapat pengaruh positif signifikan antara Kepatuhan pada K3 terhadap Zero accident

Kriteria uji hipotesis adalah jika nilai signifikansi < 0,05, maka Ha diterima dan Ho ditolak; jika nilai signifikansi > 0,05, maka Ha ditolak dan Ho diterima.

Tabel 4. Korelasi antara Kepatuhan pada K3 terhadap zero accident

\begin{tabular}{|c|c|c|}
\hline & Kepatuhan pada K3 & Zero accident \\
\hline $\begin{array}{c}\text { Kepatuhan pada K3 } \\
\text { Pearson corelation }\end{array}$ & 1 & .503 \\
\hline
\end{tabular}




\begin{tabular}{|c|c|c|}
\hline Sig (2-tailed) & 100 &, 000 \\
$\mathrm{~N}$ & & 100 \\
\hline Zero accident &, 503 & 1 \\
Pearson corelation &, 000 & 100 \\
Sig (2-tailed) & 100 & 1 \\
$\mathrm{~N}$ &
\end{tabular}

Sumber : Hasil Olah Data

Berdasarkan tabel 4 diketahui nilai signifikansi sebesar $0,000<0,05$ sehingga Ha diterima dan Ho ditolak. Artinya "Terdapat pengaruh positif signifikan antara Kepatuhan K3 terhadap Zero accident". Koefisien pengaruh antara Kepatuhan pada K3 terhadap zero accident adalah sebesar 50,3\%. Kepatuhan pada K3 (X2) berpengaruh positif terhadap Zero accident $(\mathrm{Y})$ dengan koefisien korelasi sebesar 0,503 . Adanya hubungan positif ini berarti kepatuhan pada K3 memiliki hubungan yang searah. Nilai koefisien 0,503 dapat diartikan bahwa variabel kepatuhan pada K3 mempunyai pengaruh sebesar 50,3\% terhadap variabel zero accident, artinya memiliki hubungan yang erat.

c. Uji korelasi antara Pemahaman tentang K3 terhadap Kepatuhan pada K3

Pengujian Hipotesis III

$\mathrm{H}_{0}$ : Tidak terdapat pengaruh positif signifikan antara pemahaman $\mathrm{K} 3$ terhadap Kepatuhan pada K3

$\mathrm{H}_{\mathrm{a}}$ : Terdapat pengaruh positif signifikan antara pemahaman tentang $\mathrm{K} 3$ terhadap Kepatuhan pada K3

Kriteria uji hipotesis adalah jika nilai signifikansi $<0,05$, maka $\mathrm{H}_{\mathrm{a}}$ diterima dan $\mathrm{H}_{0}$ ditolak; jika nilai signifikansi > 0,05, maka $\mathrm{H}_{\mathrm{a}}$ ditolak dan $\mathrm{H}_{0}$ diterima.

Tabel 5. Korelasi antara Pemahaman tentang K3 terhadap Kepatuhan pada K3

\begin{tabular}{|c|c|c|}
\hline & Pemahaman tentang K3 & Kepatuhan pada K3 \\
\hline Pemahaman tentang K3 & 1 & .641 \\
Pearson corelation & 100 &, 000 \\
Sig (2-tailed) & & 100 \\
N &, 641 & 1 \\
Kepatuhan pada K3 &, 000 & 100 \\
Pearson corelation & 100 & \\
Sig (2-tailed) & & \\
N & &
\end{tabular}

Sumber : Hasil Olah Data

Berdasarkan tabel 5 diketahui nilai signifikansi sebesar $0,000<0,05$ sehingga $\mathrm{H}_{\mathrm{a}}$ diterima dan $\mathrm{H}_{0}$ ditolak. Artinya "Terdapat pengaruh positif signifikan antara Pemahaman tentang K3 terhadap Kepatuhan pada K3". Koefisien pengaruh antara Pemahaman tentang K3 terhadap Kepatuhan pada K3 adalah sebesar 64,1\%. Pemahaman tentang K3 (X1) berpengaruh positif terhadap Kepatuhan pada K3 (X2) dengan koefisien korelasi sebesar 0,641. Adanya hubungan positif ini berarti memiliki hubungan yang searah. Nilai koefisien 0,641 dapat diartikan bahwa variabel pemahaman tentang K3 mempunyai pengaruh sebesar $64,1 \%$ terhadap variabel kepatuhan pada $\mathrm{K} 3$, artinya memiliki hubungan yang erat.

d. Uji regresi linier berganda antara variabel Pemahaman tentang K3 dan Kepatuhan pada K3 terhadap variabel Zero accident

Pengujian Hipotesis 4:

$\mathrm{H}_{0}$ : Tidak terdapat pengaruh positif signifikan antara Pemahaman K3 dan Kepatuhan K3 terhadap zero accident

$\mathrm{H}_{\mathrm{a}}$ :Terdapat pengaruh positif signifikan antara Pemahaman K3 dan Kepatuhan K3 terhadap zero accident

Uji regresi berganda digunakan untuk mengetahui kontribusi variabel independen yaitu variabel Pemahaman tentang K3 di Perusahaan (X1) dan Kepatuhan pada K3 terhadap variabel Y Zero accident. Berikut disajikan hasil pada tabel 6 sebagai berikut: 
Tabel 6. Hasil Uji regresi variabel Pemahaman dan variabel Kepatuhan terhadap variabel Zero accident

\begin{tabular}{|c|c|c|}
\hline $\mathrm{R}$ & R Square & Adjusted R Square \\
\hline $0,602^{\mathrm{a}}$ & 0,362 & 0,349 \\
\hline
\end{tabular}

Sumber: Hasil olah data

Berdasarkan hasil koefisien determinasi pada nilai Adjuted $R$ Square adalah 0,349 Nilai ini dapat diartikan bahwa sebesar 34,9\% koeffisien dari Pemahaman tentang K3 dan Kepatuhan pada K3 terhadap Zero accident, sedangkan sisanya $65,1 \%$ dipengaruhi oleh faktor-faktor lain diluar variabel tersebut.

Secara umum hasil pengujian hipotesis pengaruh antara variabel pemahaman tentang K3, variabel kepatuhan pada K3, dan variabel zero accident dapat diringkas pada tabel 7 berikut

Tabel 7. Tabel Ringkasan Hasil Pengujian

\begin{tabular}{|c|c|c|}
\hline Hipotesis & Koefisien & Hasil Uji \\
\hline $\begin{array}{c}\text { Terdapat Pengaruh Pemahaman tentang K3 } \\
\text { terhadap zero accident }\end{array}$ & 0,576 & $\mathrm{H}_{0}$ Ditolak \\
\hline $\begin{array}{c}\text { Terdapat Pengaruh Kepatuhan pada K3 terhadap } \\
\text { zero accident }\end{array}$ & 0,503 & $\mathrm{H}_{0}$ Ditolak \\
\hline $\begin{array}{l}\text { Terdapat Pengaruh Pemahaman pada K3 terhadap } \\
\text { Kepatuhan pada K3 }\end{array}$ & 0,641 & $\mathrm{H}_{0}$ Ditolak \\
\hline $\begin{array}{l}\text { Terdapat Pengaruh Pemahaman pada K3 dan } \\
\text { Kepatuhan pada K3 terhadap zero accident }\end{array}$ & 0,349 & $\mathrm{H}_{0}$ Ditolak \\
\hline
\end{tabular}

Sumber : Hasil olah data

\section{Kesimpulan}

Bahwa pelaksanaan SMK3 untuk mempertahankan zero accident dipengaruhi secara positif signifikan oleh variabel pemahaman tentang K3 dan variabel kepatuhan pada k3 dengan kontribusi sebesar 34,9\%. Pemahaman tentang K3 (X1) berpengaruh positif terhadap Kepatuhan pada K3 (X2) dengan koefisien regresi sebesar $64,1 \%$. Pemahaman tentang $\mathrm{K} 3\left(\mathrm{X}_{1}\right)$ berpengaruh positif terhadap Zero accident $(\mathrm{Y})$ dengan koefisien regresi sebesar $57,6 \%$. Kepatuhan pada $\mathrm{K} 3\left(\mathrm{X}_{2}\right)$ berpengaruh positif terhadap Zero accident (Y) dengan koefisien regresi sebesar 50,3\%.

\section{Daftar Referensi}

[1] Hanim, F. Zulhafiza. 2016. Safety and Health Practices and Injury Management in Manufacturing Industry. Procedia Economic and Finance 35 pp. 705-712

[2] Nordlof, H. Wiitavaara, B. 2017. A Cross-sectional Study of Factors influencing Occupational Health and Safety Management Practices in Companies. Jurnal Elsevier Safety Science 95 pp. 92-103

[3] Zahyanti, N. 2013. Komitmen Kebijakan Keselamatan dan Kesehatan Kerja (K3) Sebagai Upaya Perlindungan Terhadap Tenaga Kerja (Studi pada Mitra Produksi Sigaret (MPS) KUD Tani Mulyo Lamongan). Jurnal Administrasi Publik Vol. 11 No. 2 h. 264-275

[4] Nujhani, J. Ika, J. 2013. Evaluasi Penerapan Sistem Manajemen Keselamatan dan Kesehatan Kerja (SMK3) pada Proyek Persiapan Lahan Pusri IIB PT. Pupuk Sriwidjaja Palembang. Jurnal Teknik Sipil dan Lingkungan Vol. 1 No. 1 h. 80-85

[5] Calcedo. Gonzalez. 2015. Analysis on Integrated Management of The Quality, Environment, and Safetyon The Industrial Projects. Procedia Engineering 132 pp.140-145

[6] Jesus. Jose. 2018. Safety Management System in TQM Environments. ElsevierSafety Science 101 pp.135-143

[7] Topalovic, S. 2015. The Implementation of Total Quality Management in order to Improve Production Performance and Enhancing The Level of Customer Satisfaction. Science Direct : Procedia Technology pp. 1016-1022 
[8] Catarina. Wijayanto, A. 2012. Pengaruh Keselamatan dan Kesehatan Kerja Terhadap Prestasi Kerja Karyawan Pada PT. PLN (persero) APJ Semarang, Jurnal Administrasi Bisnis Vol. 1 No. 1 h. 1-11

[9] Kartikasari, R. Swasto, B. 2017. Pengaruh Keselamatan dan Kesehatan Kerja Karyawan terhadap Kinerja Karyawan (Studi pada Karyawan Bagian ProduksiPT. Surya Asbes Cement Group Malang). Jurnal Administrasi Bisnis Vol. 44 No. 1 h. 79-95

[10] Marom, E. Sunuharyo, B. 2018. Pengaruh Keselamatan Kerja (K3) terhadap kinerja karyawan (studi pada karyawan bagian produksi perusahaan PT. Lion Metal Works Tbk). Jurnal Administrasi Bisnis (JAB) Vol. 60 No. 1 h. 187-194

[11] Wahyuni, N.Suyadi, B. Hartanto,W. 2018. Pengaruh Keselamatan dan Kesehatan Kerja (k3) terhadap Produktivitas Kerja Karyawan pada PT. Kutai Timber Indonesia (Studi kasus pada PT. Kutai Timber Indonesia Kota Probolinggo). Jurnal Pendidikan Ekonomi Vol. 12 No. 1 h. 99-103

[12] Rahadian, D. Nursanti, E. Gustopo, D. 2015. Perencanaan Kontrol Kecelakaan Kerjamenuju Zero Accident pada industri pabrik gula NBH. Jurnal Teknologi dan Manajemen Industri Vol.1 No. 21 h. $17-21$

[13] Syahrizal. 2015. Analisis Strategi Penanggulangan Kecelakaan Kerja untuk Mencapai Tingkat Kecelakaan Kerja Nihil (zerro accident) pada PT. Tasik Raja. Jurnal Al-Irsyad Vol. V No. 1 h. 86-105

[14] Dharma, AAB. Putera, GAA. Parami, AAD. 2017. Manajemen Risiko Keselamatan dan Kesehatan Kerja (K3) pada proyek pembangunan Jambuluwuk Hotel \& Resort Petitenget. Jurnal Spektran Vol. 5 No.1 h. 47-55

[15] Zwetsloot, G. Kines, P. 2017. The Importance of Commitment, Communication, Culture and Learning for The Implementation of The Zero Accident Vision in 27 Companies in Europe. Jurnal Elsevier Safety Science 96 pp. 22-32

[16] Zwetsloot, G. Aaltonen, M. 2013. The Case for Research into The Zero Accident Vision. Jurnal Elsevier Safety science 58 pp.41-48

[17] Milkva, M. Prajova, V. 2016. Standardization-One of The Tools of Continuous Improvement. Jurnal Procedia Engineering 149 pp.329-332

[18] Rahayu, EP. 2015. Hubungan antara Pengetahuan, Sikap, dan Perilaku Karyawan dengan Penerapan Manajemen Keselamatan dan Kesehatan Kerja. Jurnal Kesehatan Komunitas Vol 2 No. 6 h. 289-293 